\title{
Spinal Cord Injuries and Sexual Life Satisfaction in Male Patients: What Do We Know About?
}

\author{
Gualter Andrade Junior ${ }^{1 *}$, Francisco Barroso ${ }^{1}$, Roger Alves ${ }^{1}$, Luiz Felipe Fernandes ${ }^{1}$, Juan Rodriguez ${ }^{2}$, \\ Júlia Cauduro ${ }^{2}$, Alana de Andrade ${ }^{3}$ and André Mancini ${ }^{4}$ \\ ${ }^{1}$ Resident doctor from Urology service at Getúlio Vargas University Hospital (HUGV), Brazil \\ ${ }^{2}$ Medical School of Federal University of Amazonas (UFAM), Brazil \\ ${ }^{3}$ Medical School of Pará State University (UEPA), Brazil
}

${ }^{4}$ MD, Professor of Urology service at Getúlio Vargas University Hospital (HUGV), Brazil

*Corresponding author: Gualter Andrade Junior, Getúlio Vargas University Hospital (HUGV): Avenida Apurinã, Manaus,

Amazonas, Brazil

\begin{tabular}{|c|c|}
\hline ARTICLE INFO & ABSTRACT \\
\hline Received: 㓞 August 06, 2019 & Citation: Gualter Andrade J, Francisco B, Roger A, Luiz Felipe F, Juan Rodriguez, Júlia \\
\hline Published: 蔧 August 13, 2019 & $\begin{array}{l}\text { C, Alana de A, André Mancini. Spinal Cord Injuries and Sexual Life Satisfaction in Male } \\
\text { Patients: What Do We Know About?s. Biomed J Sci \& Tech Res 20(3)-2019. BJSTR. } \\
\text { MS.ID.003465. }\end{array}$ \\
\hline
\end{tabular}

\section{Introduction}

Spinal cord injuries are prevalent these days. This prevalence is due to increase in number of cases at the expense of changes in etiology and epidemiology. Currently, spinal cord injury is mainly related to motor vehicle accidents, falls from high heights, and gunshot wounds and has a higher incidence in developing countries [1]. The sequelae resulting from these traumas are one of the major concerns in the follow-up of trauma patients since they affect motor, sensitive, autonomic, and psychological areas. Within the area of urology, in turn, one of the most frequent complaints is the change in the quality of sexual function [2]. There are already several meta-analyses that address and describe the experience of sexuality of patients who have suffered spinal cord trauma with sequelae, but there are still points that can be analyzed and addressed with more excellent care, as these patients' sex lives deserve a more holistic approach, paying attention to the stigmas and prejudices that may be linked to the situation [3]. Regarding erectile dysfunction, there are varied patterns of injuries that can cause this same type of sequelae. When only paraplegia is reported, that is, when lower levels of the spinal cord have been affected, erectile function is usually present, but one should always be attentive to physical examination for confirmation. Neurological assessment and rehabilitation in trauma patients between T11-L2 and S2-S5 are recommended, especially in the initial approach [4]. This assessment of the individual should start from a thorough interview based on tools that help in stratifying the problem. Use of the International Index of Erectile Function (IIEF-5) is recommended, as are the Male Sexual Quotient (MSQ) and Sexual Health Inventory for Men (SHIM), a more detailed version of IIEF-5 [5].

The use of these scores is necessary because they help to quantify more specifically the severity of the patient's dysfunction, especially when first approached by the medical team to serve as a complementary assessment in case of treatment or rehabilitation. in order to observe the patient's evolution and physical improvements [3]. Rehabilitation by physiotherapy is also recommended and helps significantly in improving the condition [6,7]. Regarding the psychological aspect of the patient, it must be understood that sex life is closely related to the quality of life, especially within a stable union. Recent research shows that satisfaction within sexual intercourse is of utmost importance for men, at a slightly higher level than for females. Also, other research shows that the natural fall in erectile function inherent in age also causes psychological damage within marital life. However, the most frequent complaints about erection quality are reported by women. This is because 
male patients do not seek treatment for these comorbidities [8]. Probably shame and social stigma are the leading causes of this condition because they are inserted in a society that imposes "gross" masculinity and virility as the ideal, in which the man who needs medical help is considered weak or less manly. Human cultures like this justify why only $7 \%$ of patients in new research report medication or other treatments, even though $64 \%$ of patients have reported deficiency of some degree in erectile function $[9,10]$.

Fitting this scenario in a young patient who, in most cases, already has psychological damage from the initial cause of spinal cord injury and paraplegia, it is observed that the impact on sexual satisfaction is usually catastrophic [11]. Sex life is compromised early and abruptly, even if initially not the primary concern [12]. In married men, the literature reports a decrease in the frequency of relationships in patients who still have a satisfactory erectile function, as well as a lack of confidence in initiating the sexual act. Interestingly, most patients within the study had problems with sexual intercourse but did not seek help from a specialist [13]. However, no justification analysis for this finding was reported in the study. The incidence of divorce was high in paraplegic patients, but the change in sex life did not justify it. As mentioned earlier, there are many other implications for the quality of life and psychological condition of those who have had spinal cord injury that may cause a host of other conflicts in social life [5]. In patients who were single before the injury, there is another problem: social shame. Within society, the belief that impotence affects all paraplegic patients is widespread and negatively affects the patient's psychological state and interpersonal relationships [14]. Therefore, men who experience this type of trauma are more reserved and have difficulties in interpersonal relationships at any level, not just in the sexual sphere. Multidisciplinary follow-up is therefore essential for them, as self-esteem is usually low and correct management can positively influence their quality of life [15].

\section{Conclusion}

Undeniably, monitoring the sexuality of paraplegic patients is hugely complicated. The social weight of physical disability dramatically affects men's lives, and at this point, evaluation with the psychology team should be mandatory whenever possible. Quality of erectile function should be a focus of treatment by the urology team, especially in more severe cases with significant erectile dysfunction. However, it is essential to note that many patients may not initially complain of sexual problems due to fear or shame. In such cases, any member of the healthcare team or professionally responsible for the patient should interrogate the patient for erection-related problems and encourage expert follow-up if deemed necessary. The last point to remember is the importance of the work of the multidisciplinary team. If the patient accepts only medical treatment, their follow-up will be more sporadic and will have therapeutic failures and gaps. Psychology, physiotherapy, nursing, and other areas should always be available and open to the most intense and frequent approach of these patients. Thus, it is possible to have more stimulation to the improvement and recovery of a type of dysfunction so frequent in patients with spinal cord trauma and still so little diagnosed and discussed.

\section{References}

1. Ding H, Zhou H, Wei Z, Liu L, Pan D, Feng S (2018) Epidemiology of worldwide spinal cord injury: a literature review. J Neurorestoratology 6:1-9.

2. Flynn KE, Lin L, Bruner DW, Cyranowski JM, Hahn EA, et al. (2016) Sexual Satisfaction and the Importance of Sexual Health to Quality of Life Throughout the Life Course of U. S. Adults. J Sex Med 13(11): 1642-1650.

3. Akman RY, Çelík EC, Karataş M (2015) Sexuality and sexual dysfunction in spinal cord-injured men in Turkey. Turkish J Med Sci 45(4): 758-761.

4. Denil J, Ohl DA, Smythe C (1996) Vacuum Erection Device in Spinal Cord Injured Men: Patient and Partner Satisfaction. Arch Phys Med Rehabil 77(8): 750-753.

5. Miranda EDP, Gomes CM, Bessa J de, Abdo CHN, Bellucci CHS, et al. (2016) Evaluation of Sexual Dysfunction in men with Spinal Cord Injury using the Male Sexual Quotient. Arch Phys Med Rehabil 97(6): 947-952.

6. Alexander M, Courtois F, Elliott S, Tepper M (2017) Improving Sexual Satisfaction in Persons with Spinal Cord Injuries: Collective Wisdom. Top Spinal Cord Inj Rehabil 23(1): 57-70.

7. Alexander CJ, Sipski ML, Findley TW (1993) Sexual Activities, Desire, and Satisfaction in Males Pre- and Post-Spinal Cord Injury. Arch Sex Behav 22(3): 217-228.

8. Gomes CM, Miranda EP, Bessa J De, Bellucci CHS, Battistella LR, et al. (2017) Erectile Function Predicts Sexual Satisfaction in Men with Spinal Cord Injury. Sex Med 5(3): e148-155.

9. Morrison BF, White-gittens I, Smith S, John SS, Bent R, et al. (2017) Evaluation of sexual and fertility dysfunction in spinal cord-injured men in Jamaica. Spinal Cord Ser Cases 3: 17026.

10. Mulhall J, King R, Glina S, Hvidsten K (2008) Importance of and Satisfaction with Sex Among Men and Women Worldwide: Results of the Global Better Sex Survey. J Sex Med 5(4): 788-795.

11. Rowen TS, Stein S, Tepper M (2015) Sexual Health Care for People with Physical Disabilities. J Sex Med 12(3): 584-589.

12. Taleporos G, Mccabe MP (2002) The Impact of Sexual Esteem, Body Esteem, and Sexual Satisfaction on Psychological Well-being in People with Physical Disability. Sex Disabil 20(3): 177-183.

13. Abrams KS (1981) The impact on marriages of adult-onset paraplegia. Spinal Cord 19(4): 253-259.

14. Aikman K, Np F, Oliffe JL, Ed M, Kelly MT, et al. (2018) Sexual Health in Men with Traumatic Spinal Cord Injuries: A Review and Recommendations for Primary Health-Care Providers. Am J Men's Health 12(6): 2044-2054.

15. Brown DJ, Hill ST, Baker HWG (2006) Male fertility and sexual function after spinal cord injury. Prog Brain Res 152: 427-439. 
ISSN: 2574-1241

DOI: 10.26717/BJSTR.2019.20.003465

Gualter Andrade Junior. Biomed J Sci \& Tech Res

cC) This work is licensed under Creative Commons Attribution 4.0 License

Submission Link: https://biomedres.us/submit-manuscript.php

$\begin{array}{ll}\text { BIOMEDICAL } & \text { Assets of Publishing with us } \\ \text { RESEARCHES } & \text { - Global archiving of articles } \\ \text { - Immediate, unrestricted online access } & \text { - Rigorous Peer Review Process } \\ & \text { - Authors Retain Copyrights } \\ \end{array}$

